\title{
Engineering of Nitrosomonas europaea to express Vitreoscilla hemoglobin enhances oxygen uptake and conversion of ammonia to nitrite
}

\author{
Stephanie A Kunkel ${ }^{1,2}$, Krishna R Pagilla ${ }^{2}$ and Benjamin C Stark ${ }^{1 *}$
}

\begin{abstract}
Nitrosomonas europaea was transformed with a recombinant plasmid bearing the gene (vgb) encoding the hemoglobin (VHb) from the bacterium Vitreoscilla under control of the N. europaea amoC P1 promoter. Vgb was maintained stably and appeared to be expressed in the transformants at VHb levels of about $0.75 \mathrm{nmol} / \mathrm{g}$ wet weight. Expression of $\mathrm{VHb}$ in the $\mathrm{N}$. europaea transformants was correlated with an approximately 2 fold increase in oxygen uptake rate by whole cells at oxygen concentrations in the range of $75-100 \%$ saturation, but no change in oxygen uptake rate at oxygen concentrations below $25 \%$ saturation. VHb expression was also correlated with an increase of as much as about $30 \%$ in conversion of ammonia to nitrite by growing cells. The results suggest that engineering of key aerobic wastewater bacteria to express bacterial hemoglobins may be a useful strategy to produce species with enhanced respiratory abilities.
\end{abstract}

Keywords: Aerobic respiration, Aerobic wastewater treatment, Engineered bacteria, Nitrosomonas europaea, Vitreoscilla hemoglobin

\section{Introduction}

One of the key functions of the aerobic portion of conventional waste water treatment (activated sludge process) is the efficient oxidation of ammonia to nitrate, because ammonia in the effluent is toxic to aquatic species when released to the environment. As the nitrifying species are relatively intolerant of low dissolved oxygen (DO) levels, the activated sludge process is run at high DO levels, ranging from a low of $2 \mathrm{mg} \mathrm{DO} / \mathrm{L}$ to as high as saturation at the ambient temperature (Rittmann and McCarty 2001). The variation is due to variations in the influent wastewater flow, concentrations of oxygen-demanding substances, and wastewater temperature. Furthermore, to avoid occurrences of less than $2 \mathrm{mg} \mathrm{DO} / \mathrm{L}$, the activated sludge process is operated

\footnotetext{
*Correspondence: starkb@iit.edu

${ }^{1}$ Department of Biology, Illinois Institute of Technology, Chicago,

IL 60616, USA

Full list of author information is available at the end of the article
}

at much higher DO levels than necessary. The energy required for the aeration in the activated sludge process to achieve these high DO levels is enormous, amounting to $45-75 \%$ of the energy required to run a waste water treatment plant (Rosso et al. 2008). Thus, development of nitrifying species and communities that can efficiently convert ammonia to nitrate at low DO levels ["demandside" strategies (Arnaldos and Pagilla 2014)] could be an important aspect of energy conservation efforts.

Nitrosomonas europaea is a key member of the bacteria responsible for the first step in nitrification, conversion of ammonia to nitrite. This conversion occurs in two steps, from ammonia to hydroxylamine, and then hydroxylamine to nitrite. The first step is catalyzed by ammonia monooxygenase, in which molecular oxygen is one of the substrates. Molecular oxygen is also the terminal electron acceptor in the electron transport chain of $N$. europaea (Rittmann and McCarty 2001).

Previously we have investigated how nitrification can be achieved at low DO by adaptation of native species

\section{Springer}


from activated sludge to growth at low DO in medium containing only ammonia as a source of electrons. In that study (Arnaldos et al. 2013), a community highly enriched in nitrifying species (including $N$. europaea) was obtained after 140 days that could efficiently convert ammonia to nitrate at DO levels of $0.1 \mathrm{mg} / \mathrm{ml}$ (about $1 \%$ of saturation). This community was also characterized by an increase in the levels of an as yet unidentified heme protein, which did not seem to be a peroxidase or any of the oxidases known to be involved in nitrification (Arnaldos et al. 2014).

An important group of heme proteins, bacterial hemoglobins, were initially discovered in 1986 in Vitreoscilla. Although the initial discovery was surprising, since then it has become apparent that bacterial hemoglobins are very common, occurring in about two thirds of all bacterial species (Vinogradov et al. 2006). There are three main classes of bacterial hemoglobins, with a number of functions, although each of these involves oxygen binding or sensing in some way (Vinogradov et al. 2006; Vinogradov and Moens 2008). It is possible, then, that the unidentified heme protein found in our earlier studies could be a hemoglobin.

The Vitreoscilla hemoglobin (VHb), the archetypical full-length single domain hemoglobin, is perhaps the best studied of all bacterial hemoglobins (Frey and Kallio 2003; Zhang et al. 2007; Stark et al. 2011, 2012, 2015). Among its functions are binding of oxygen (particularly at low DO) and delivery to the respiratory chain (Ramandeep et al. 2001; Park et al. 2002) to enhance oxidative phosphorylation at low oxygen concentrations, and to oxygenases, to enhance their activity (Fish et al. 2000; Lin et al. 2003). The gene ( $v g b$ ) encoding VHb has been cloned and transformed into a variety of bacterial, fungal, and even plant species to enhance their growth and productivity, especially under low oxygen conditions (Frey and Kallio 2003; Zhang et al. 2007; Stark et al. 2011, 2015).

The documented utility of $v g b / \mathrm{VHb}$ in recombinant organisms, the ability of $\mathrm{VHb}$ to aid oxidative phosphorylation and oxygenases, and the possibility that one or more bacterial hemoglobins may be induced in a nitrifying community as the result of low DO adaptation, led us to investigate whether engineering of N. europaea to express VHb could enhance its growth, respiration and ability to convert ammonia to nitrite. This could provide support for the idea that hemoglobins which may be important in low DO functioning occur naturally in one or more nitrifiers, as well as serving as a proof of concept that engineering nitrifiers with $v g b / \mathrm{VHb}$ might be of use in development of efficient low DO activated sludge processes.

\section{Materials and methods}

\section{Cell growth and maintenance}

Nitrosomonas europaea (ATCC 19178), received from the laboratory of Dr. Luis A. Sayavedra-Soto (Oregon State University, Corvallis, Oregon), was grown in 0.5 $\mathrm{L}$ liquid batch cultures in $1 \mathrm{~L}$ Erlenmeyer flasks in the dark at $30^{\circ} \mathrm{C}$ with gentle agitation $(\sim 120 \mathrm{rpm})$ in $50 \mathrm{mM}$ ammonium medium (Hyman and Arp 1992). Medium for transformed $N$. europaea cultures contained $25 \mu \mathrm{g} /$ $\mathrm{mL}$ ampicillin.

\section{Construction of plasmid pSK2}

Plasmid pUC8:16 ( $v g b$ cloned into the HindIII-SalI sites of $E$. coli vector pUC8; Liu et al. 1994) was cleaved at its HindIII site. A synthetic sequence identical to the N. europaea amoC P1 promoter (Hommes et al. 2001; Berube et al. 2007) was produced from two complementary oligonucleotides (Integrated DNA Technologies, Coralville, IA) that were $5^{\prime}$ phosphorylated by T4 polynucleotide kinase and annealed by heating to $95^{\circ} \mathrm{C}$ for $10 \mathrm{~min}$ followed by slow cooling to room temperature. Because of the design of the two oligonucleotides, the annealed product had 4 bp single stranded HindIII compatible overhangs at each end, which allowed sticky end ligation into the HindIII site in pUC8:16 to produce pSK2. This placed the amoC P1 promoter just upstream of the native $v g b$ promoter (Fig. 1). The $a m o C$ P1 promoter was previously found to be active in the presence of ammonia (Hommes et al. 2001) and is thus a good candidate for expression of $v g b$ for these studies. Because of its derivation from pUC8:16, pSK2 confers resistance to ampicillin.

\section{Electroporation of pSK2 into N. europaea}

$N$. europaea cells were grown in $0.5 \mathrm{~L}$ cultures in the ammonia medium described above to an $\mathrm{OD}_{600 \mathrm{~nm}}$ of $\sim 0.1$, collected by centrifugation and washed three times. The washed cell pellet was resuspended in deionized $\mathrm{H}_{2} \mathrm{O}$ and chilled on ice for $30 \mathrm{~min}$, and $100 \mu \mathrm{L}$ of cell suspension mixed with $1 \mu \mathrm{L}(1 \mu \mathrm{g})$ pSK2 in a prechilled $1 \mathrm{~mm}$ gap electroporation cuvette. The cuvette was placed into a BTX ECM 630 Exponential Decay Wave Electroporation System (Harvard Apparatus Inc., Holliston, MA) and pulsed once at $1,200 \mathrm{~V}, 25 \mathrm{mF}$ and a resistance larger than 100 ohms. Immediately after pulsing, the cells were transferred to $0.5 \mathrm{~L}$ prewarmed ammonia medium and grown for $24 \mathrm{~h}$ under non-selective conditions at $30^{\circ} \mathrm{C}$ and $100 \mathrm{rpm}$ shaking. After $24 \mathrm{~h}$ ampicillin was added to a concentration of $25 \mu \mathrm{g} / \mathrm{mL}$. Transformant cultures grew up after 7-14 days and they were usually maintained as liquid cultures due to the extreme difficulty in isolating colonies on plates as well the slow growth time 


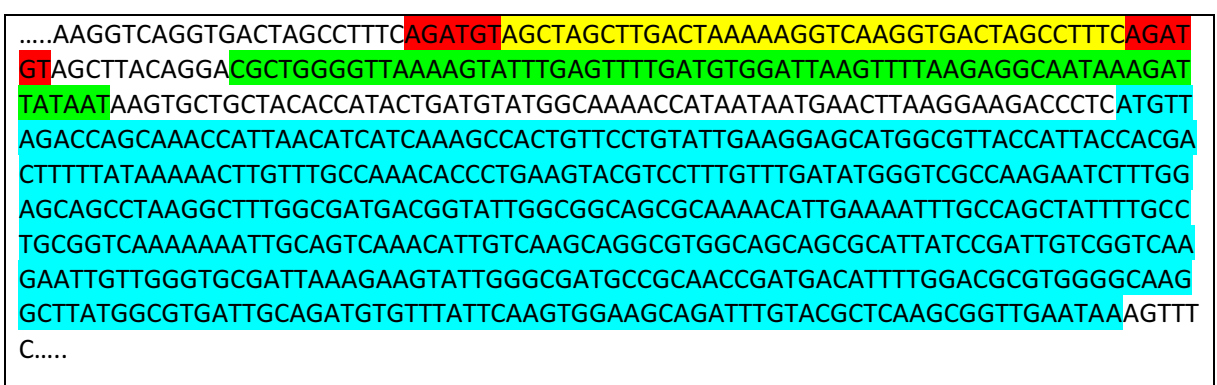

Fig. 1 Sequence of plasmid PSK2 in the region of $v g b$ and the integrated amoC P1 promoter. The amoC promoter is highlighted in yellow, with the flanking Hindlll sites highlighted in red. The native vgb promoter region is highlighted in green, and the vgb coding sequence, beginning with the ATG start codon and ending with the TAA stop codon, is highlighted in turquoise.

(3-4 weeks) and fast decay on solid medium (1-2 weeks) (Sayavedra-Soto and Stein 2011).

\section{Plasmid purification and PCR}

Plasmid preps were performed using the E.Z.N.A. Plasmid Mini Kit (Omega Bio-Tek, Norcross, GA) according to the manufacturer's instructions. PCR analysis was also done on the plasmids in order to amplify $v g b$ from (positive control) pUC8:16 (Vgb1/Vgb2 primer set) and the amo1 promoter along with $v g b$ from pSK2 (AmoCp1/ Vgb2 primer set). These primers and the annealing temperatures used are listed in Table 1. The PCR program used was the following: step $1-94^{\circ} \mathrm{C}$ for $5 \mathrm{~min}$, step $2-94^{\circ} \mathrm{C}$ for $30 \mathrm{~s}$, step 3-temperature dependent on primer used (Table 1 ) for $30 \mathrm{~s}$, step $4-72^{\circ} \mathrm{C}$ for $1 \mathrm{~min}$ and $15 \mathrm{~s}$, step $5-72^{\circ} \mathrm{C}$ for $5 \mathrm{~min}$ and step 6 -held at $4^{\circ} \mathrm{C}$; amplification cycle (steps $2-4$ ) repeated 30 times.

\section{CO-difference spectra}

0.5 L cultures of $N$. europaea, and $N$. europaea[pSK2] were grown for 5 days as described in "Introduction" section above, and $5 \mathrm{~mL}$ cultures of $E$. coli DH5 $\alpha$ [pUC8:16] were grown in $\mathrm{LB}$ medium in $15 \mathrm{~mL}$ culture tubes at $37^{\circ} \mathrm{C}$ and $200 \mathrm{rpm}$. Preparation of cell extracts and CO-difference spectra determination on them (600-400 nm with a sampling interval of $1 \mathrm{~nm}$ ) were done as described by Dikshit and Webster (1988) using a Shimadzu UV-1800 spectrophotometer.

\section{Nitrite assay}

Nitrite production from ammonia was measured in culture samples using the spectrophotometric method of Hageman and Hucklesby (1971).

\section{Oxygen uptake measurements}

Two $0.5 \mathrm{~L}$ cultures each of untransformed $N$. europaea and $N$. europaea[pSK2] cells were harvested in log phase, after approximately 2-3 days of growth and at an $\mathrm{OD}_{600 \mathrm{~nm}}$ of approximately 0.05 ; the exact $\mathrm{OD}_{600 \mathrm{~nm}}$ of each culture at the time of harvesting was recorded. The cells were pelleted by centrifugation and washed three times with deionized water, and the resulting pellet resuspended in $40 \mathrm{~mL}$ of the appropriate Nitrosomonas growth medium (ammonia medium either without antibiotics or containing $25 \mu \mathrm{g} / \mathrm{mL}$ ampicillin) at room temperature in a $50 \mathrm{~mL}$ flask. Due to the slow growth and overall low density of Nitrosomonas europaea, the rate of oxygen uptake in these experiments was quite slow. For this reason the OUR experiments were performed in two portions, the first measuring oxygen uptake in an initially fully saturated medium, therefore starting at $100 \%$ saturation and reading down to about $80 \%$ saturation, and the second portion starting at around $25 \%$ and finishing as close to zero as possible. The fully saturated medium was bubbled with air for $30 \mathrm{~min}$ prior to the start of each assay in order to ensure $100 \%$ oxygen saturation. The low oxygen medium was prepared in the same way except

Table 1 PCR primers used for amplification of $\mathrm{vgb}$ and the amo1 promoter

\begin{tabular}{lll}
\hline Primer & Sequence $\left(\mathbf{5}^{\prime} \mathbf{- 3}\right)$ & Annealing temp ( $\left.{ }^{\circ} \mathbf{C}\right)$ \\
\hline Vgb1 & GCG CGG AAT TCA TGT TAG ACC AGC AA & \\
Vgb2 & GCG CGC TCG AGT TAT TCA ACC GCT TG & \\
AmoCp1 & AGCTAG CTT GACTAA AAA GGT CAA GGT GACTAG CCTTTC AGA TGT & $59(60)^{*}$ \\
\hline
\end{tabular}

* Annealing temperature used for the primer pair. 
prior to the OUR assay the oxygen level was reduced to $25 \%$ saturation by addition of sodium dithionite.

OUR values were measured using a 5331 oxygen probe connected to a 5300A oxygen monitor (YSI, Yellow Springs, $\mathrm{OH}$ ), which was calibrated before each assay according to the manufacturer's instructions and then was used immediately following calibration to ensure accuracy. Immersion of the probe into the cell suspension caused the initial volume to rise, thus leaving no headspace. The conversion from per cent saturation to $\mathrm{mg} / \mathrm{L}$ oxygen was determined on the basis of assay temperature and salinity.

\section{Results}

We were able to transform $N$. europaea using two $v g b$ bearing plasmids which we had previously constructed. These included pUC8:16 (Dikshit and Webster 1988; Liu et al. 1994), in which $v g b$ with its native (low oxygen responsive) promoter is cloned into the $E$. coli vector pUC8 (Vieira and Messing 1982) and pRESX-vgb, $v g b$ cloned into the Rhodococcus-E. coli shuttle vector pRESX (van der Gieze et al. 2008), in which $v g b$ transcription is driven by a Rhodococcus type promoter. In neither case, however, was VHb expressed, presumably because of incompatibility between promoter and host RNA polymerase.

Following this we obtained the sequence of the $a m o C$ P1 promoter from $N$. europaea from the literature (Hommes et al. 2001) and had it synthesized, and cloned it into our existing plasmid pUC8:16, producing plasmid pSK2. This construction maintains the native Vitreoscilla promoter upstream of the transcriptional start point but inserts the $N$. europaea promoter upstream of the Vitreoscilla promoter. The correct construct was confirmed by DNA sequencing (Fig. 1).

Transformation of $N$. europaea with pSK2 was successful and stable with antibiotic pressure $(25 \mu \mathrm{g} / \mathrm{mL}$ ampicillin), as proven by miniprep analysis and PCR amplification of $v g b$ repeated at 2 week intervals (Fig. 2). In addition, this construct allowed production of $\mathrm{VHb}$ in $N$. europaea, as demonstrated by CO-difference spectral analysis.

$\mathrm{VHb}$ has a characteristic CO-difference spectrum with a peak at $419 \mathrm{~nm}$ and trough at $436 \mathrm{~nm}$ (Dikshit and Webster 1988; Fig. 3a). A CO-difference spectrum of a whole cell extract of untransformed $N$. europaea has several peaks, the most prominent of which is at $414 \mathrm{~nm}$ (Arnaldos et al. 2013; Fig. 3b). The identity of this peak is as yet unknown. CO-difference spectra of eight individual $N$. europaea/pSK2 transformants showed the $414 \mathrm{~nm}$ peak shifted from 414 to $416 \mathrm{~nm}$ with a shoulder at about $423 \mathrm{~nm}$ (three examples shown in Fig. 3c). The shift and shoulder are consistent with an overlap or combination

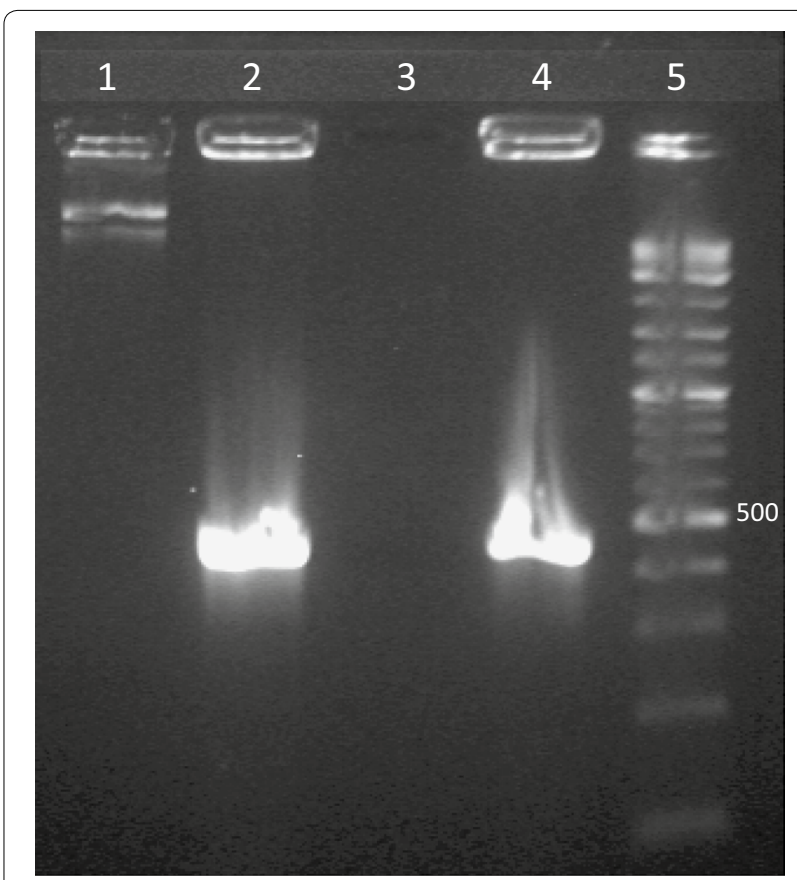

Fig. 2 pSK2 is stably maintained in N. europaea[pSK2]. Lane 1 pSK2 plasmid prep from N. europaea [pSK2]; lane 2 positive control PCR of $v g b$ amplicon (from pUC8:16 from E. coli); lane 3 negative control PCR of $\mathrm{vgb}$ (plasmid prep from untransformed N. europaea); lane 4 PCR amplicon of $v g b$ from N. europaea [pSK2]; lane 5 2-log ladder (New England Biolabs; position of 500 bp fragment is noted). The amplicons in lanes 2 and 4 are of the expected size (about $450 \mathrm{bp}$ ).

of the $414 \mathrm{~nm}$ peak and the characteristic $419 \mathrm{~nm} \mathrm{VHb}$ peak, the 423 shoulder presumably being part of the $\mathrm{VHb}$ signal. Although it is difficult to quantify the level of $\mathrm{VHb}$ from the height of the 423 shoulder, the average of calculations from three independent $N$. europaea[pSK2] spectra yielded a value of about $0.75 \mathrm{nmol} / \mathrm{g}$ wet weight of cells.

The transformant was compared with the untransformed control strain regarding respiration (SOUR) at both high oxygen concentration (starting at 100\% saturation) as well as low oxygen concentration (starting at $25 \%$ saturation) (Fig. 4). Starting at $100 \%$ DO the SOUR of the transformant was substantially greater than that of the untransformed strain (Fig. 4a), but starting at lower DO the SOUR of the two strains was essentially identical (Fig. 4b).

The transformant was also compared with the untransformed control strain regarding production of nitrite from ammonia during growth in ammonia medium (Fig. 5). These experiments were conducted from $\mathrm{OD}_{600 \mathrm{~nm}}$ 's of about 0.008-0.104 (corresponding to growth during 5 days following inoculation). Earlier in the growth phase $\left(\mathrm{OD}_{600 \mathrm{~nm}}\right.$ up to about 0.02 , or about 2 days) the expression of $\mathrm{VHb}$ was correlated with an approximately $30 \%$ increase 

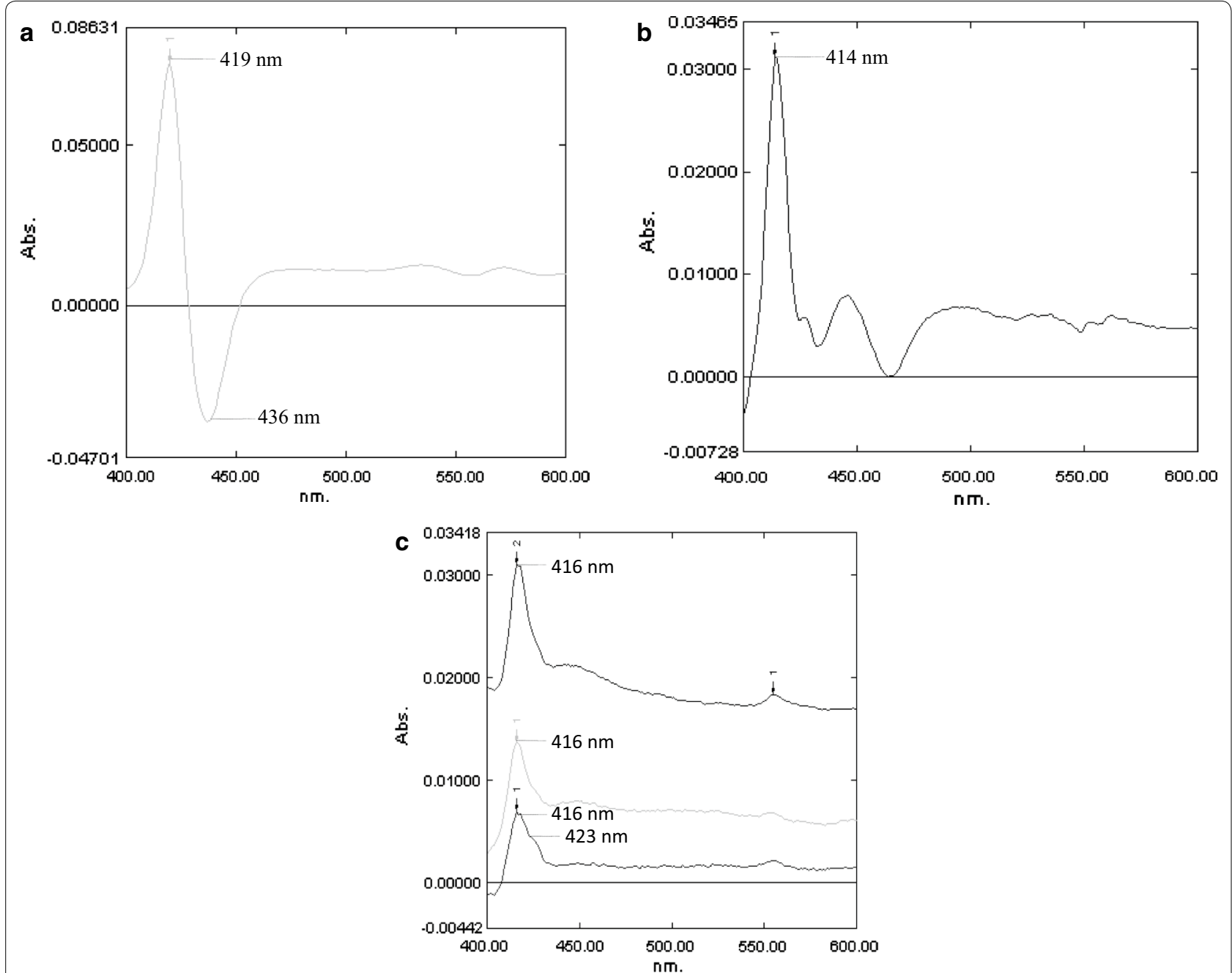

Fig. 3 CO-difference spectral analysis. a CO-difference spectrum of cell extract of E. coli DH5a[pUC8:16] expressing VHb; peak and trough at 419 and $436 \mathrm{~nm}$, respectively, characteristic of $\mathrm{VHb}$ are indicated. b CO-difference spectrum of cell extract of untransformed N. europaea; characteristic peak at $414 \mathrm{~nm}$ is indicated. c CO-difference spectra of cell extracts from three individual isolates of N. europaea transformed with $\mathrm{vgb}$ on plasmid pSK2; peak at $416 \mathrm{~nm}$ and shoulder at $423 \mathrm{~nm}$ are indicated.

in nitrite conversion per unit of cell mass compared to the untransformed strain; the transformant's advantage decreased gradually to only about $6 \%$ by $\mathrm{OD}_{600 \mathrm{~nm}}$ of about 0.10 (about 5 days of growth).

\section{Discussion}

Plasmid pSK2 is a derivative of the Messing vector pUC8 and thus has a ColEI type replication origin, native for $E$. coli. We have not been able to find any previous studies in which a ColEI replication origin is recognized in $N$. europaea. One mechanism of ColEI replication initiation requires both host RNA polymerase and RNase $\mathrm{H}$, and $N$. europaea does have the latter enzyme (Chain et al. 2003); RNase $\mathrm{H}$ independent mechanisms for initiation of ColE1 replication also exist (Dasgupta et al. 1987). In any case, we were able to transform $N$. europaea with pSK2 many times, and frequent plasmid preparations and PCR amplification of $v g b$ from these transformants confirmed that pSK2, once transformed into N. europaea, was stably maintained.

The level of VHb measured in N. europaea[pSK2] is much lower than the induced level in native Vitreoscilla (30 nmol/g wet weight of cells; Dikshit and Webster 1988) or in recombinant $E$. coli expressing $\mathrm{VHb}$ from the native $v g b$ promoter (hundreds of $\mathrm{nmol} / \mathrm{g}$ wet weight of cells; Dikshit and Webster 1988). Levels of VHb in a variety of other heterologous hosts are substantially lower (Patel et al. 2000; Liu et al. 1995; Dogan et al. 2006). The lowest level which we have seen that is correlated with an apparent positive effect is $4 \mathrm{nmol} / \mathrm{g}$ wet weight (in Gordonia 

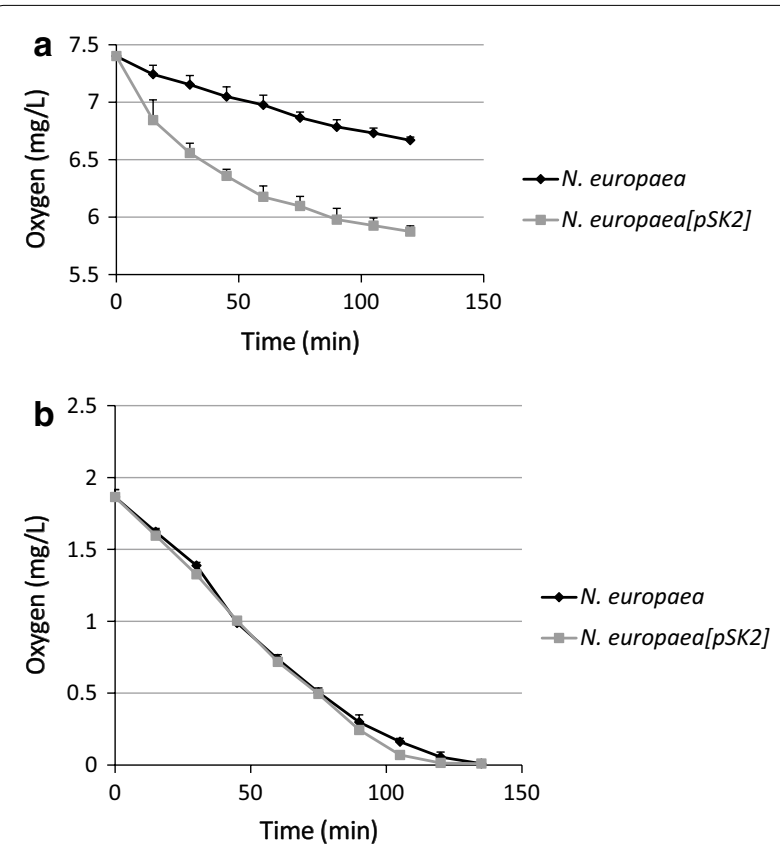

Fig. 4 Oxygen uptake measurements for N. europaea[pSK2] (gray squares and gray line) and untransformed $N$. europaea (black diamonds and black line). a Measurements made starting with DO at 100\% saturation. b Measurements made starting with DO at 25\% saturation. All points are averages of five independent experiments; for every experiment at both initial oxygen concentrations and for both strains, the same mass of cells $\left(0.06 \mathrm{OD}_{600 \mathrm{~nm}}\right)$ was tested. Error bars indicate standard deviations (which in some cases are smaller than the diameter of the symbols).

amarae; Dogan et al. 2006). The results presented here suggest that an even lower $\mathrm{VHb}$ level can provide benefits to a recombinant bacterium.
The dissociation constant, $K_{d}$ for oxygen of $\mathrm{VHb}$ when expressed in either E. coli or Vitreoscilla is $6 \mu \mathrm{M}$ (approximately $2.3 \%$ of oxygen saturation at room temperature), and this is the DO range at which one might expect the presence of $\mathrm{VHb}$ to have the greatest effect on oxygen uptake rates (Webster 1987). The opposite, however, was observed. There was a substantial increase in SOUR correlated with the presence of VHb from 100\% to about $80 \%$ oxygen saturation (about 231 to about $181 \mu \mathrm{M}$ ), but no difference in SOUR between the transformed and untransformed strains from 25 to $0 \%$ saturation (about $58-0 \mu \mathrm{M}$ ). The reasons for this are unknown, but it is known that several of the $\mathrm{VHb}$ functions depend upon its interaction with "partner proteins" (Stark et al. 2012, 2015), and it may be that the partners with which it might interact in $N$. europaea alter its oxygen binding properties.

In any event, the increased SOUR coincident with apparent $\mathrm{VHb}$ expression may be related to the enhancement of ammonia to nitrite conversion seen for $N$. europaea. This enhancement appears to be such that the conversion per unit of cell mass is greater rather than being due to an increase in cell mass. Two mechanisms by which this might occur are enhanced delivery of oxygen to the end of the respiratory chain (Ramandeep et al. 2001; Park et al. 2002) to enhance ATP production and thus general cell robustness (for example, greater levels of ammonia monooxygenase) or delivery directly to ammonia monooxygenase to enhance its activity. The latter mechanism appears to be the case for at least one other oxygenase (Fish et al. 2000; Lin et al. 2003).

Even if the advantages provided by the $v g b$-expressing $N$. europaea strain or other engineered VHb-expressing

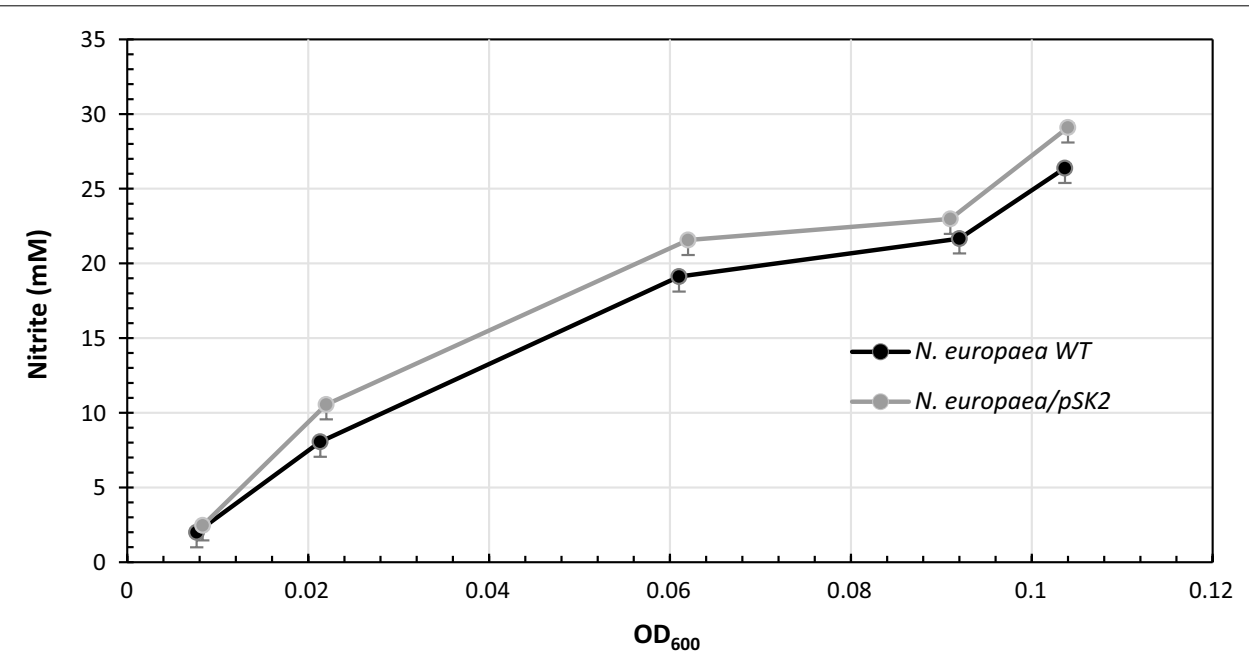

Fig. 5 Ammonia to nitrite conversion as a function of cell mass $\left(\mathrm{OD}_{600 \mathrm{~nm}}\right)$ for growing cultures of N. europaea[pSK2] and untransformed N. europaea. Each point is the average of 10 independent experiments; error bars indicate standard deviations. 
bacteria are great enough to be of practical usefulness, it is probably not reasonable to augment sludge in an actual treatment plant with such cells. Bacteria that express hemoglobins (full-length single domain (VHb-like) and truncated) that are known or thought to be involved in oxygen binding and delivery (Hill et al. 1996; Thorsteinsson et al. 1999; Pathania et al. 2002; Wainwright et al. 2005; Stark et al. 2011, 2012) are known to occur naturally in a number of normal sludge bacteria. The work described here suggests that the expression of $\mathrm{VHb}$ in a key activated sludge species may, in fact, enhance sludge performance in regard to oxygen utilization. This then suggests that enhancement of the growth of the natural hemoglobin-expressing sludge flora, or enhancement of horizontal transfer of the hemoglobin genes to other species within the sludge, may be successful demandside strategies regarding sludge aeration. Such strategies might impact both nitrification and removal of organic carbon from wastewater.

\section{Author details}

${ }^{1}$ Department of Biology, Illinois Institute of Technology, Chicago, IL 60616, USA. ${ }^{2}$ Present Address: Department of Civil, Architectural and Environmental Engineering, Illinois Institute of Technology, Chicago, IL 60616, USA.

\section{Acknowledgements}

We thank Dr. Luis A. Sayavedra-Soto (Oregon State University, Corvallis, Oregon) for the kind gift of $N$. europaea.

\section{Compliance with ethical guidelines}

\section{Competing interests}

The authors declare that they have no competing interests.

\section{Consent for publication}

This article does not contain any studies with human participants or animals performed by any of the authors.

Received: 18 June 2015 Accepted: 23 July 2015

Published online: 01 August 2015

\section{References}

Arnaldos M, Pagilla KR (2014) Implementation of a demand-side approach to reduce aeration requirements of activated sludge systems: directed acclimation of biomass and its effect at the process level. Water Res 62:147-155

Arnaldos M, Kunkel SA, Stark BC, Pagilla KR (2013) Enhanced heme protein expression by ammonia-oxidizing communities acclimated to low dissolved oxygen conditions. Appl Microbiol Biotechnol 97:10211-10221

Arnaldos M, Kunkel SA, Stark BC, Pagilla KR (2014) Characterization of heme protein expressed by ammonia-oxidizing bacteria under low dissolved oxygen conditions. Appl Microbiol Biotechnol 98:3231-3239

Berube PM, Samudrala R, Stahl DA (2007) Transcription of all amoC copies is associated with recovery of Nitrosomonas europaea from ammonia starvation. J Bact 189:3935-3944

Chain P, Lamerdin J, Larimer F, Regala W, Lao V, Land M et al (2003) Complete genome sequence of the ammonia-oxidizing bacterium and obligate chemolithoautotroph Nitrosomonas europaea. J Bact 185:2759-2773

Dasgupta S, Masukata H, Tomizawa J (1987) Multiple mechanisms for initiation of ColE1 replication: DNA synthesis in the presence and absence of Ribonuclease H. Cell 51:1113-1122
Dikshit KL, Webster DA (1988) Cloning, characterization and expression of the bacterial globin gene from Vitreoscilla in Escherichia coli. Gene 70:377-386

Dogan I, Pagilla KR, Webster DA, Stark BC (2006) Expression of Vitreoscilla hemoglobin in Gordonia amarae enhances biosurfactant production. J Indust Microbiol Biotechnol 33:693-700

Fish PA, Webster DA, Stark BC (2000) Vitreoscilla hemoglobin enhances the first step in 2,4-dinitrotoluene degradation in vitro and at low aeration in vivo. J Molec Catalysis B Enzymatic 9:75-82

Frey AD, Kallio PT (2003) Bacterial hemoglobins and flavohemoglobins: versatile proteins and their impact on microbiology and biotechnology. FEMS Microbiol Rev 27:525-545

Hageman RH, Hucklesby DP (1971) Nitrate reductase in higher plants. Methods Enzymol 23:491-503

Hill DR, Belbin TJ, Thorsteinsson MV, Bassam D, Brass S, Ernst A et al (1996) GlbN (cyanoglobin) is a peripheral membrane protein that is restricted to certain Nostoc spp. J Bact 178:6587-6598

Hommes NG, Sayavedra-Soto LA, Arp DJ (2001) Transcript analysis of multiple Copies of amo (encoding ammonia monooxygenase) and hao (encoding hydroxylamine oxidoreductase) in Nitrosomonas europaea. J Bact 183:1096-1100

Hyman MR, Arp DJ (1992) ${ }^{14} \mathrm{C}_{2} \mathrm{H}_{2}$ - and ${ }^{14} \mathrm{CO}_{2}$-labeling studies of the de novo synthesis of polypeptides by Nitrosomonas europaea during recovery from acetylene and light inactivation of ammonia monooxygenase. J Biol Chem 267:1534-1545

Lin JM, Stark BC, Webster DA (2003) Effects of Vitreoscilla hemoglobin on the 2,4-dinitrotoluene (DNT) dioxygenase activity of Burkholderia and on DNT degradation in two-phase bioreactors. J Indust Microbiol Biotechnol 30:362-368

Liu SC, Liu YX, Webster DA, Stark BC (1994) Sequence of the region downstream of the Vitreoscilla hemoglobin gene: $v g b$ is not part of a multigene operon. Appl Microbiol Biotechnol 42:304-308

Liu SC, Webster DA, Stark BC (1995) Cloning and expression of the Vitreoscilla hemoglobin gene in Pseudomonads: effects on cell growth. Appl Microbiol Biotechnol 44:419-424

Park KW, Kim KJ, Howard AJ, Stark BC, Webster DA (2002) Vitreoscilla hemoglobin binds to subunit I of cytochrome bo ubiquinol oxidases. J Biol Chem 277:33334-33337

Patel SM, Stark BC, Hwang KW, Dikshit KL, Webster DA (2000) Cloning and expression of Vitreoscilla hemoglobin gene in Burkholderia sp. strain DNT for enhancement of 2,4-dinitrotoluene degradation. Biotechnol Prog 16:26-30

Pathania R, Navani NK, Rajamohan G, Dikshit KL (2002) Mycobacterium tuberculosis hemoglobin $\mathrm{HbO}$ associates with membranes and stimulates cellular respiration of recombinant Escherichia coli. J Biol Chem 277:15293-15302

Ramandeep, Hwang KW, Raje M, Kim KJ, Stark BC, Dikshit KL, Webster DA (2001) Vitreoscilla hemoglobin: intracellular localization and binding to membranes. J Biol Chem 276:24781-24789

Rittmann BE, McCarty PL (2001) Environmental biotechnology: principles and applications. McGraw-Hill, New York

Rosso D, Stenstrom MK, Larson LE (2008) Aeration of large-scale municipal wastewater treatment plants: state of the art. Water Sci Technol 57:973-978

Sayavedra-Soto LA, Stein LY (2011) Genetic transformation of ammonia oxidizing bacteria. Meth Enzymol 486:389-402

Stark BC, Dikshit KL, Pagilla KR (2011) Recent advances in understanding the structure, function, and biotechnological usefulness of the hemoglobin from the bacterium Vitreoscilla. Biotechnol Lett 33:1705-1714

Stark BC, Dikshit KL, Pagilla KR (2012) The Biochemistry of Vitreoscilla hemoglobin. Computat Struct Biotechnol J 3:e201210002

Stark BC, Dikshit KL, Pagilla KR (2015) Recent applications of Vitreoscilla hemoglobin technology in bioproduct synthesis and bioremediation. Appl Microbiol Biotechnol 99:1627-1636

Thorsteinsson MV, Bevan DR, Potts M, Dou Y, Eich RF, Hargrove MS et al (1999) A cyanobacterial hemoglobin with unusual ligand binding kinetics and stability properties. Biochemistry 38:2117-2126

Van der Gieze R, Hessels Gl, Nienhuis-Kuiper M, Dijkhuizen L (2008) Characterization of a second Rhodococcus erythropolis SQ1 3-ketosteroid 9-alphahydroxylase activity comprising a terminal oxygenase homologue, KshA2, active with oxygenase-reductase component KshB. Appl Environ Microbiol 74:7197-7203 
Vieira J, Messing J (1982) The pUC plasmids, an M13mp7-derived system for insertion mutagenesis and sequencing with synthetic universal primers. Gene 19:259-268

Vinogradov SN, Moens L (2008) Diversity of globin function: enzymatic, transport, storage, and sensing. J Biol Chem 283:8773-8777

Vinogradov SN, Hoogewijs D, Bailey X, Arredondo-Peter R, Gough J, Dewilde S et al (2006) A phylogenomic profile of globins. BMC Evol Biol 6:31

Wainwright LM, Elvers KT, Park SF, Poole RK (2005) A truncated haemoglobin implicated in oxygen metabolism by the microaerophilic food-borne pathogen Campylobacter jejuni. Microbiology 151:4079-4091
Webster DA (1987) Structure and function of bacterial hemoglobin and related proteins. In: Eichorn GC, Marzilli LG (eds) Advances in inorganic biochemistry, vol 7. Elsevier, New York, pp 245-265

Zhang L, Li Y, Wang Z, Xia Y, Chen W, Tang K (2007) Recent developments and future prospects of Vitreoscilla hemoglobin applications in metabolic engineering. Biotechnol Adv 25:123-136

\section{Submit your manuscript to a SpringerOpen ${ }^{\circ}$ journal and benefit from:}

- Convenient online submission

- Rigorous peer review

- Immediate publication on acceptance

- Open access: articles freely available online

- High visibility within the field

- Retaining the copyright to your article

Submit your next manuscript at $\boldsymbol{~ s p r i n g e r o p e n . c o m ~}$ 